\title{
وسائط الفنون المعاصرة من المفاهيمية الى الهولوجرام
}

\author{
الباحثة هند عمر الثبيتي
}

\section{المخلص - (الم}

إن تقنية الهولوجرام فيزيائية المنشأ طرحت العديد من الاسئله والامكانات حول ما يمكن اخراجه من أعمال وتقنيات مرتبطة بالبعد الثالث و صناعة الصورة في الفراغ ،يمكن وصف الصورة الهولوجراميه بأنها تمثيل ايهامي باستخدام أشعة الليزر أو الضوء لاعطاء البعد الثالث على افلام لوحية أو في صورة تجسيميه ، تم تطبق هذه الطرق التصويريه في مجالات الدعاية والاعلان والمعارض الفنيه في دول اخرى ، ولعل تطبيقات الهولوجرام الفنيه هذه هي التي أثارت تساؤلات الباحثة حول امكانية الاستفادة من تقنية الهولوجرام كمدخل لاستحداث أعمال تصويرية مجسمة لإثراء الفن السعودي المعاصر ، وأثارت فضولها لتجربة فن الهولوجرام عمليا ـ وتهدف الباحثة من خلال تجربتها العمليه الى التعرف على تقنية الهولوجرام ودورها في استحداث اعمال مجسمه تصويريه تواكب التطورات التكنولوجية المعاصرة واللحاق بركب الدول المتقدمه في هذا المجال ، وكذلك استثمار فن الهولوجرام في تغيير مظاهر وأثكال الاعمال التصويرية المجسمة لإثراء الفن السعودي المعاصر لانتاج اعمال تصويرية تمثل حياة المجتمع السعودي وتحديات الحضارة في زمننا المعاصر بتقنية الهولوجرام ـ لتحقيق هدف من اهداف رؤية المملكة العربية السعودية التي ترمي الى اكتثاف طرق جديده للاستثمار في الفنون البصريه.وبما أن تقنيه الهولوجرام هي من التقنيات المتطورة التي تتحدث بسرعه هائله وبامكانات لا تتواجد في المملكه السعودية بوفرة فان الباحثة ترمي بتجربتها هذه الى توفير مرجع تاريخي للراغبين بتجربة الفنون الهولوجراميه في مجال الفنون ورفع مستوى المخرج الفني السعودي المعاصر . الكلمات المفتاحية : هواوجرام ، فنون بصريه ، فن معاصر ، تكنولوجيا ، تجسيم تتلخص مشكلة البحث في : القاء الضوء على تأثير المفاهيمية على الفنون ووسائطها المتتوعه وظهور فن الهولوجراممن خلال البحث في بداياته وماهيته .

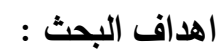

$$
\begin{aligned}
& \text { 1- يهدف البحث الى القاء الضوء على ابرز التقنيات والمفاهيم المعاصرة . } \\
& \text { 2- - - التعرف على ماهية الهولوجرام وامكاناته فنياً. }
\end{aligned}
$$

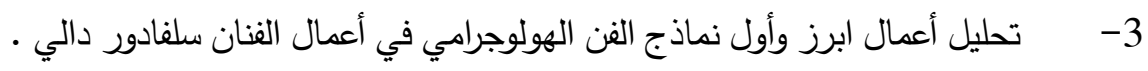

$$
\begin{aligned}
& \text { 4- عرض تجربة الباحثة التصوريه لاعمال هولوجراميه. }
\end{aligned}
$$

1- دراسة إضافة الهولوجرام كعنصر لبناء العمل وتحقيق البعد الدرامي والديناميكي في فكر سلفادور دالي بهدف اثراء الفن العربي المعاصر تقنية ومضموناً. 
2- ابراز دور التكنولوجيا والتتنيات المعاصرة وبالأخص الهولوجرام كأداة في الاعمال والعروض الفنيه.

3- تزويد المكتبة العربية بأبحاث تتناول تقنية الهولوجرام نظرا لندرة المراجع.

منهج البحث

تتبع الباحثة المنهج التاريخي من خلال الاطار النظري: الذي فيه يتم التعرف على بدايات ظهور تقنية الهولوجرام في الفن وابرز الفنانين الذين استخدمها وكذلك المنهج الوصفي التحليلي من خلال الإطار النظري في المحاور التالية :

• الفن المعاصر والتكنولوجيا

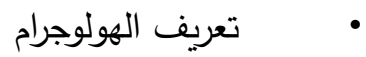

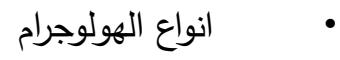

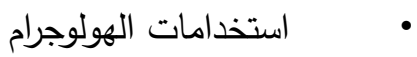

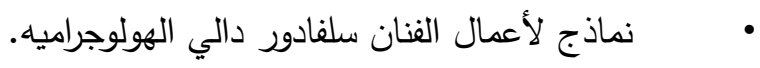

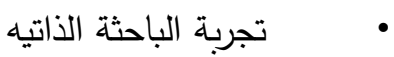

فروض البحث: إن تقنيه الهولوجرام تسهم في استحداث واثراء العمل الفني العربي المعاصر •

و كذلك تتبع الباحثة المنهج التجريبي: من خلال تتفيذ تجربة ذاتية تصوريه تهدف لإثراء الفن العربي المعاصر من خلال

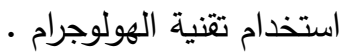

حدود البحث

الحدود الزمانية : تقتصر الدراسة على دراسة الفنون المعاصرة منذ مطلع القرن الواحد والعشرين وتحليل التقنيات

المستحدثة والمرتبطة بالتكنولوجيا المعاصرة في التصوير التثكيلي منذ عام 2000 الى وقت انتهاء الدراسة.

الحدود المكانية : المملكة العربية السعودية.

الفن المعاصر والتكنولوجيا

ان من نعم التكنولوجيا المعاصرة من بداية تكونها وصولا الى ما وصلت اليه هي فرضها لواقع جديد مختلف و متجدد ساهم في افراز فنانين ذوي رؤية جديدة بتجدد الحياة وأدواتها ، وذلك الامر صاحبه تغيرات اجتماعية وجمالية القت بظلالها على هلى الفنون بشكل أو باخر كما ترى الباحثة ، وبذلك فان تفاعل الفنان التشكيلي مع هذا التقدم والتتور هو تفاعل مرحلي يبدا بالمعرفة ثم القبول ثم الانتثار • ويوافق الكاتب علاء الخطيب رأي الباحثه في مقاله في جريدة الديار اللندنيه حيث قال:" لقد

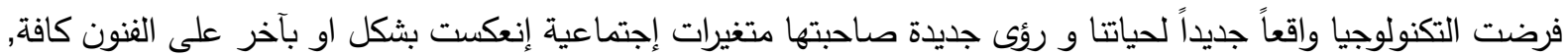
ومنها الفن التثكيلي ".

ويمكن القول بان صراع الفرادة في العمل الفني يرجع تاريخه لبداية دمج الفن والتكنولوجيا و من اختراع الكاميرا بالتحديد وان اهم سؤالين دائرين منذ ذلك الحين هما : أين هو العمل الفني وأين يكون ؟ وذلك بحسب مائ دايكل راش في كتابه الوسائط 
الجديدة في الفن ، وترى الباحثة أن هذا المفهوم تضخم وتفاقم بظهور تكنولوجيا العالم الرقمي الافتراضي الذي فرض التحدي على الفنون بتعريف العمل الفني بتعريف اوسع لا يعنى فقط بالثكل المادي فقط بل قد يعتمد على الوجود الافتراضي والرقمي كذلك حتى شمل الفن الوسائط الجديده الغير ملسوسه كالضوء والاسقاطات والليزر والافتراضيه كذلك التي يعتمد على رؤيتها

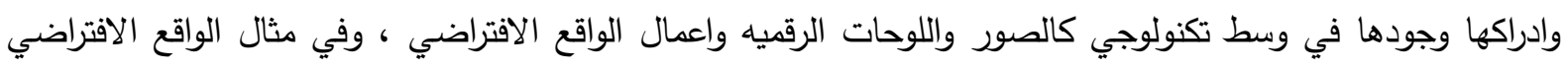

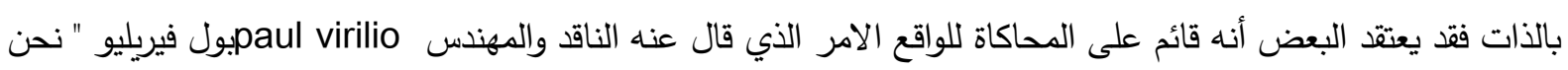

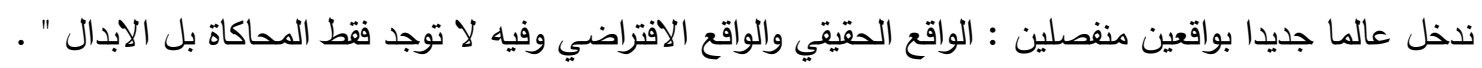

فماهي التكنولوجيا او لما يرمز هذا المصطلح عامة وفي الفن خاصة ، التكنولوجيا كلمة يونانيّة في الأصل، تتكوّن من

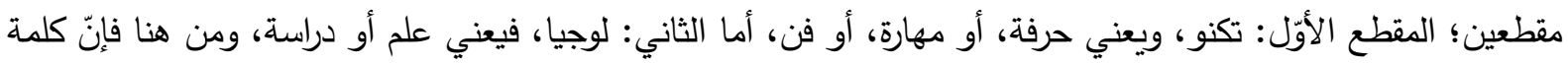

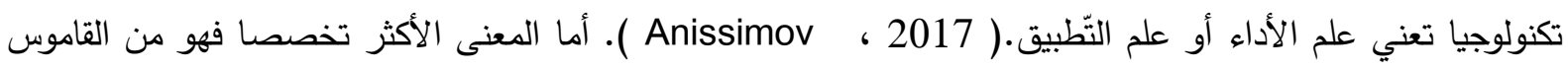

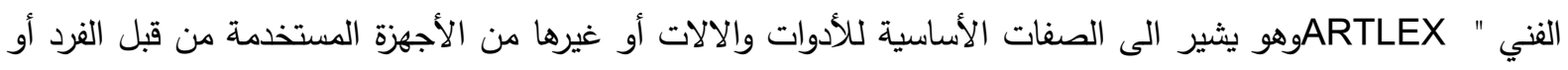

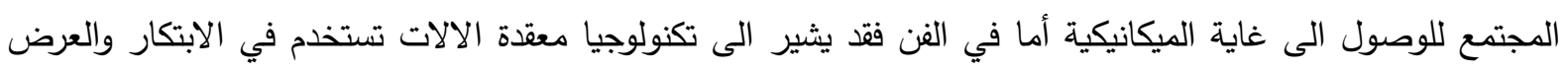

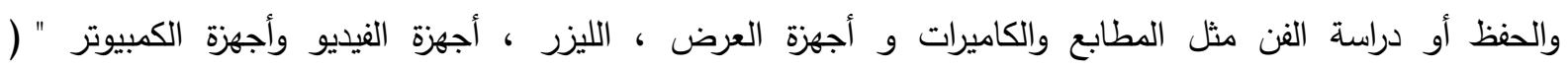
(/http://www.artcyclopedia.com

وان التكنولوجيا في سياق هذا البحث تخص التقنيات المستخدمه في الفنون عامة والفن السعودي خاصة وصولا لتقنيه العرض الهولوجرامي الفني التي كانت الافراز المباشر لاختراع صور الهولوجرام ذات البعد الثالث منذ بدايتها على الاسطح

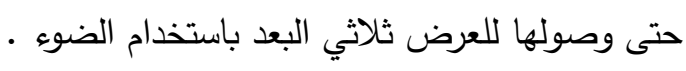

وتعرفه الباحثه (الجريان،2013 ) بأنه عبارة عن طريقة تخزين ونقل المعلومان البصرية وغيرها كأرقام في شكل نبضات متقطعه متتالية حيث تخزم المعلومات على أثكال رقميه والفنون الرقمية ماهي الا جزء من ذلك حيث التهنئ انها الاتجاه الحديث

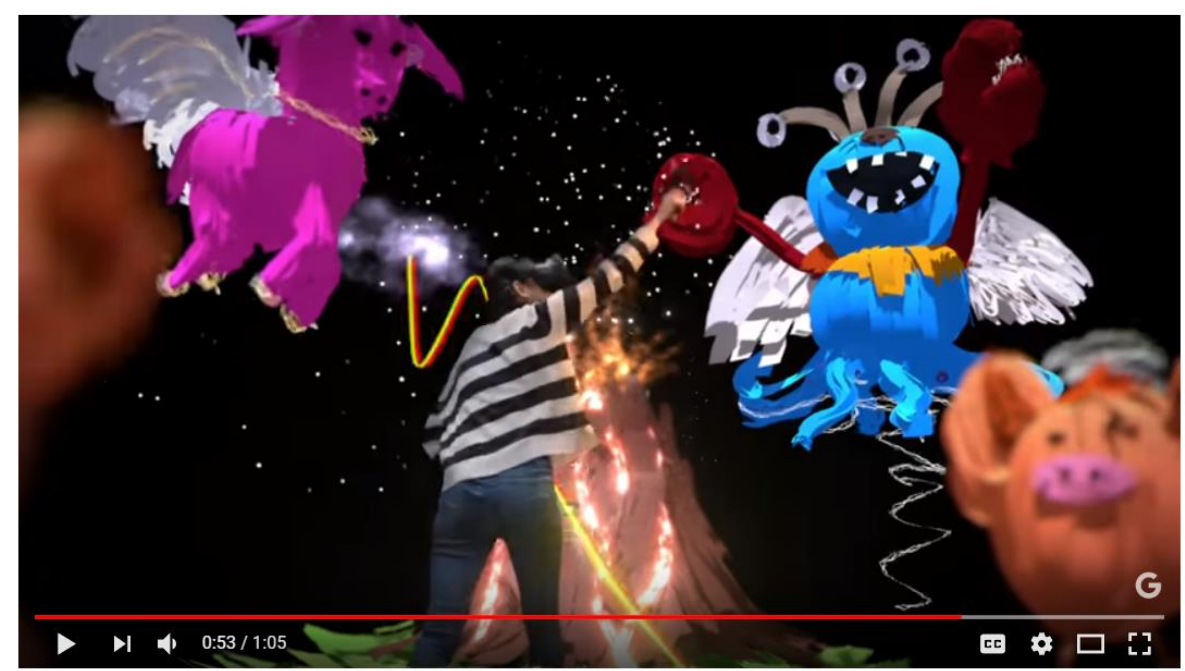

Tilt Brush: Painting from a new perspective

tilt brush الشكل 1القطات من اعلان أداة قوقل

الذي يطوع تقنيات الحاسب حيث تطرح الاعمال الفنية المنثأة من خلال الحاسب وتسمى لوحات فنية رقمية ، كما ترى أن

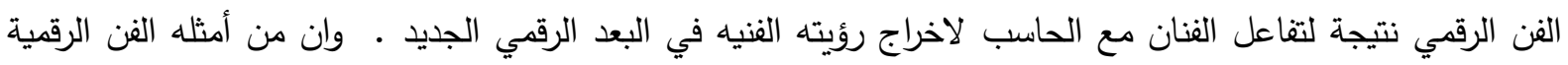

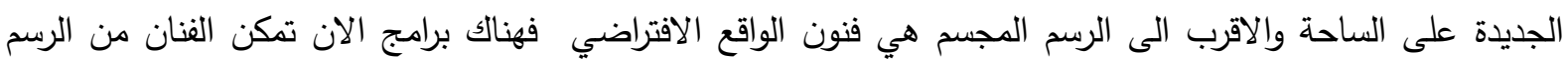


افتراضيا في فراغ باستخدام جسده كما يفعل في اللوحات التقليدية وذلك عن طريق استخدام نظارات الواقع الافتراضي وأدوات لليدين مثال عليها أداة طورتها شركة قوقل اسمها ( tilt brush) ويمكن اختيار نوع الفرشاة وسماكة ودرجة اللون كما يمكن التراجع والاعادة بل وحتى التعديل على اللوحات المجسمه افتراضيا بعد الانتهاء وذلك يكون في صيغه افتراضيه ولا يمكن رؤيتها الاعن نظارات الواقع الافتراضي كما في الصورة (قناة قوقل على اليوتيوب)

وهناك من الفنانين من فنون الرسم الرقمي الافتراضي الى مجال اوسع حيث قامو بتحريك الرسوم افتراضيا باستخدام البرامج

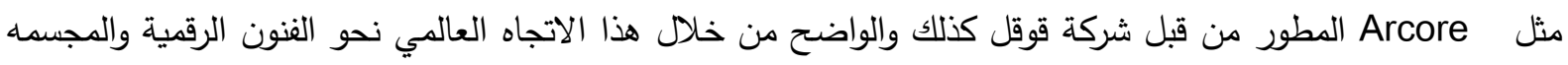

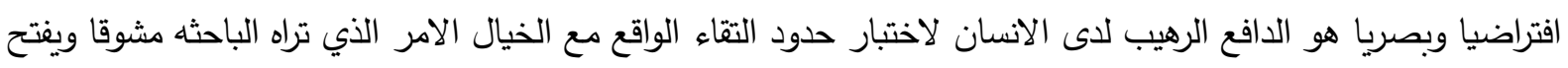

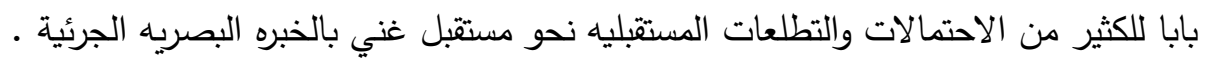

لابد من أن الاتجاه الفني نحو التكنولوجيا المعاصرة والتي تسميها الباحثة بأدوات التثكيل الجديدة هو اتجاه عالمي لم يستثنى

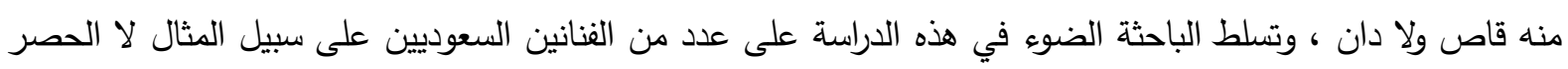
و الذين كانوا بطبيعة الحال من السباقين لتسخير وتطوير هذه التقنيات والتكنولوجيا العصرية ليخرجوا قضاياهم ورؤياهم

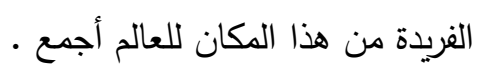

ولعل ابرز الامثلة على قوة الفن الرقمي هي الصورة واسعة الانتشار للفنان الثاب عبدالله الثهري والتي كان السبب الاول لانتشارها هو طباعتها خطأ في كتب التعليم المدرسي و في الصورة "يودا" بجانب الملك فيصل وهو التهو يوقع على ميثاق الأمم

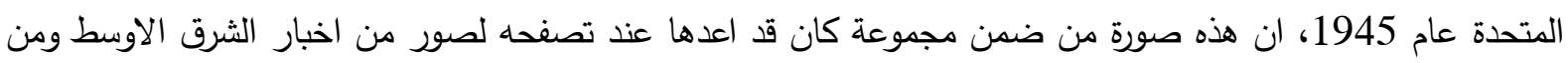
ثم ادخالها رقميا والتلاعب بها بفن التلاعب بالصور الرقمي (باستخدام برنامج تعديل الصور ) والعمل يأخذ الطابع المفاهيمي

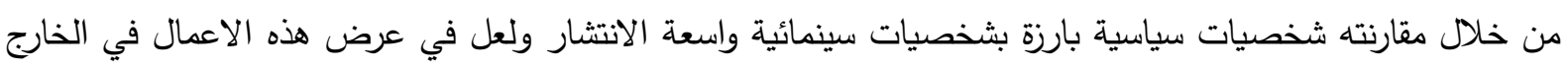

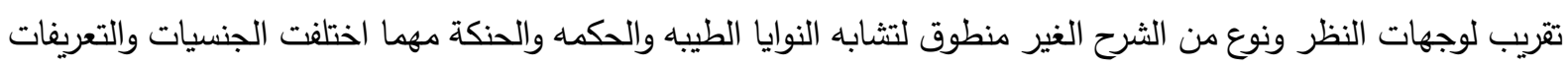
• وقال في تصريحه لصحيفة نيويورك تايمز الأمريكية أنه بدأ هذا الفن وكانت الصور التي تصفيه ونها كلها حزينة مليئة

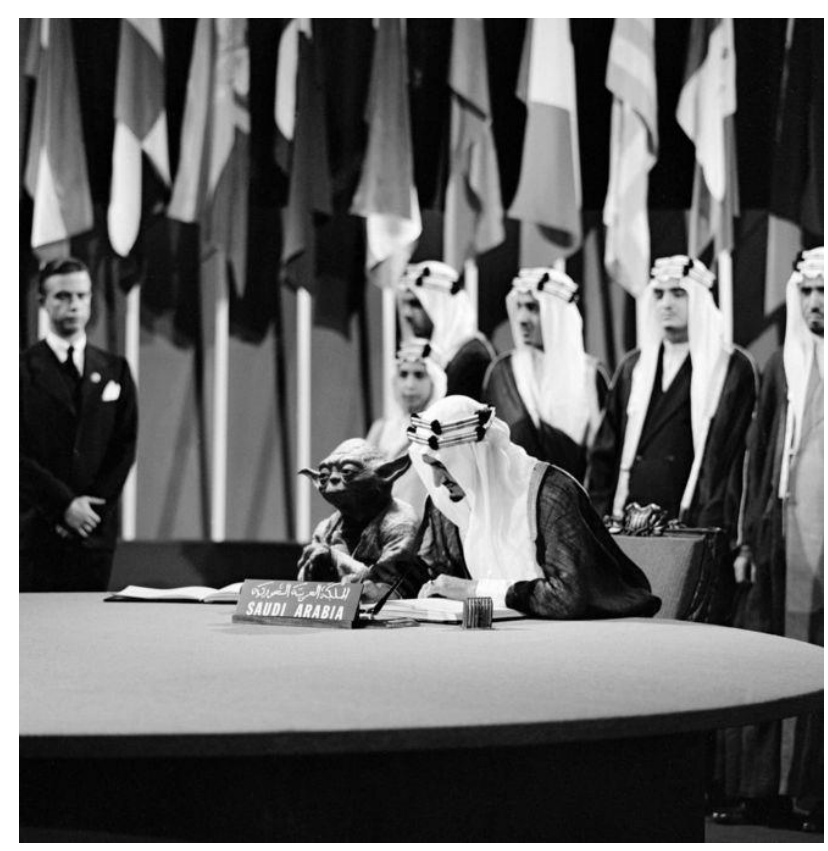

الشكل 2 عل للفنان الشاب عبدالثه الشهري 
باللاجئين والحروب، "ففكرت في إضافة بعض الثخصيات الخيالية إلى الصور الحقيقية لتشابههم في بعض الصفات والسمات".صحيفة الثرق الاوسط و الBBCالعربيه.

ومن اهم الفنانين السعودين الحاضرين على الساحة العالميه والذين لا يدخرو جهودهم في استخدام وتطويع التقنيه في سبيل الاخراج الفني عبدالناصر غارم الذي حصد خلال فترة وجيزة من حياته الفنية ، أهم الجوائز التشكيلية الفنية محليا ومنها لئه جائزة معرض الفن المعاصر 2004 وجائزة مَلْوَن, وجائزة باحة الفنون 2006 وجائزة السفير الثانية 2007 وجائزة “تواصل عن المنطقتين الغربية والجنوبية 2008. إضافة للعديد من مشاركاته الدولية عربياً وعالمياً.

تعريف الهولوجرام

كلمة هولوجرافي أصلها يوناني مشتقة من كلمة هولوس ( holos أي الكل ) و جرافو ( أ وأي الكتابة ) بمعنى سجل الصورة الكاملة أو فن التصوير المجم (حماد، 2012) ـ وقد وجب التتبيه على أن المقصود بالهولوجراف هو العمليه التي يتم من خلالها التسجيل وبناء العمل الفني أما الهولوجرام فهي تعني المنتج الابداعي النهائي المستخرج من خلال تلك العمليه ( حسان ،2013 بتصرف) وبحسب دراسة اخرى يمكن تعريف الهولوجرام بأنه صورة تسجل سعة ومرحلة موجة الضوء أي لئي

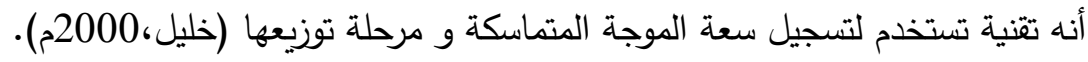

تركز فكرة الهولوجرام على التصوير المجسم الذي يختلف عن التصوير العادي في منتجه النهائي ويشابهه في انه يسجل شكلها من الواقع ثم يقوم تجسيده من خلال الضوء فاذا كانت الصورة الفوتوغرافية هي صورة مستوية ثنائية البعد حتى وان

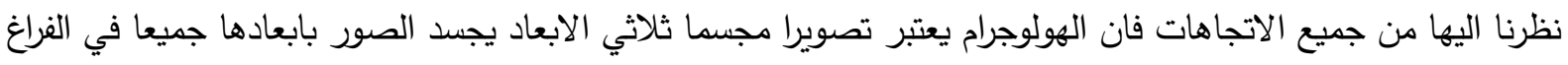
وذلك يمكن المتفرج من الالفاف حول الثكل ورؤية تفاصيل الثكل في الفراغ وكانه موجود بالواقع • وفي بدايته الهولوجرام

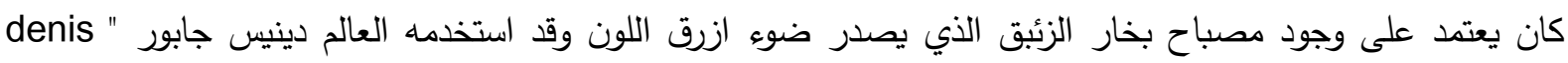

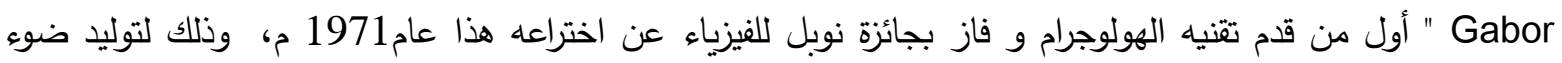

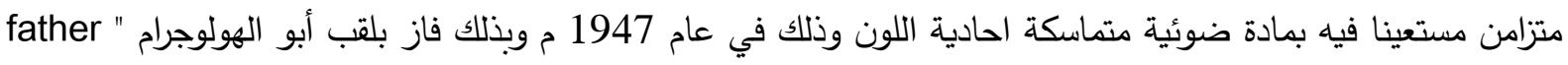
of hologram

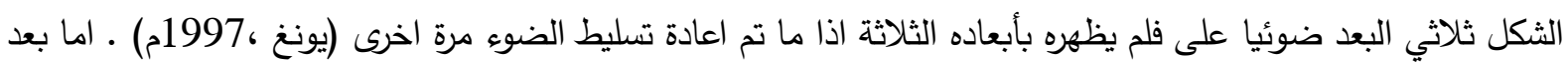

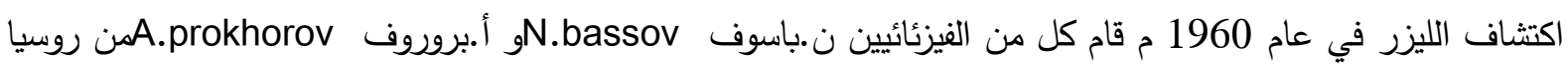
والامريكي شارلز تون Charles townبتوظيفه في مراحل العمليه الهولوجرافيه (حسان، 2013 ). و تستنبط الباحثة بذلك التعريف المبسط لتقنية الهولوجرام بانها التقنيه التي تُعنى بتجسيد الصورة ثنائية البعد لتثغل حيزا افتراضيا في الفراغ ( حيث ان الانعكاس التي تحدثه هذه التقنيه يظهر وجود الجسم للعين المجرده بدون حضوره فعليا ) . اما في ما ورد عن التثريق بين مصطلحي الهولوجرام والهولوجراف فإن الهولوجراف هو العمليه التي يتم فيها تسجيل الصور أو الاجسام بطريقه ثلاثيه الابعاد ، فان الهولوجرام فهو المنتج النهائي الذي يتضمن الثكل او التصميم الذي تم التوصل اليه بعد عمليات التسجيل الحساس (حسان ،2013 ) وبناء عليه فإنه في حاله الهولوجرام الفيلمي الذي يسجل على شرائح خاصه بإستخدام الليزر فإن الفلم يسىى هولوجرام وعمليه التسجيل يطلق عليها تسجيل هولوجرافي أي أن الهولوجراف يوجد في الهولوجرام. 
ان تطور الهولوجرام منذ بداية ظهوره اعتمد على تطور التقنيات والتجارب العلميه وتطور الفكر وراء استخدام هذه التقنيه وتطويعها وتوفيرها في يد المستخدم ، في الستينات والسبعينات وصولا للوقت الحاضر وان الاضافة الحديثة لاختراع ال LED واضافته للتصوير الهولوجرامي فتح المجال للإستخدامات العديدة والمتتوعاه وسهلة الوصول للتجارب الهولوجراميه . و يمتد الخيال العلمي الذي يرمي الى تطوير هذه التقنيه لتصل ليد المستخدمين و اشاعة استخدامها بحلول العام 2050 وما الى ذلك من التوقعات كما ذكرت مجلة الفيزياء العصرية وذلك بقلم الباحثة حنين عيد , وقد ساهم تعدد الانواع للتصوير والعرض الهولوجرامي وأذكر تصنيفين الاول للباحثة رحاب حماد والذي تعتبره الباحثة تصنيفا عاما وهو أن انواع الهولوجرام يتم تحديدها على النحو التالي :

\section{1. الهولوجرام الثريحي الرقيق plane hologram

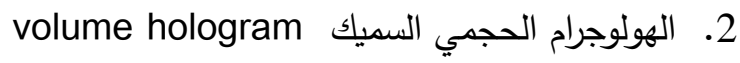

وترى الباحثة بأن الدراسة السابقة التي صنفت هذا التصنيف وضعت الخط الاساس لتقريق أشكال نتائج التصوير الهولوجرامي عامة حيث أن الهولوجرام الثريحي ( قد يسمى اللوحي كذلك) هو الذي يكون في هيئة صورة او فلم هولوجرامي ثنائي البعد وترى فيه العين تسجيلا ثلاثيا للبعد افتراض وغير واقعي أما النوع الثاني الذي يسمى الهولوجرام الحجمي (وتصطلح عليه

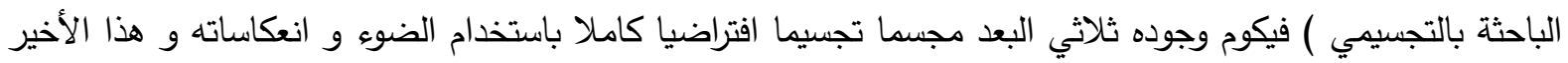

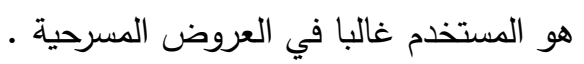

أما التصنيف الاخر فهو بحسب دراسة الباحث حسان صبحي حسان وهو أكثر تفصيلا فذكر ان انواع الهولوجرام تتوقف على نوع الجسم المراد تصويره وتفصيلياته وعمقها وطبيعة الزوايا المراد تدوينها، وحجم هذا الجسم ، وخاماته ، وكونه في

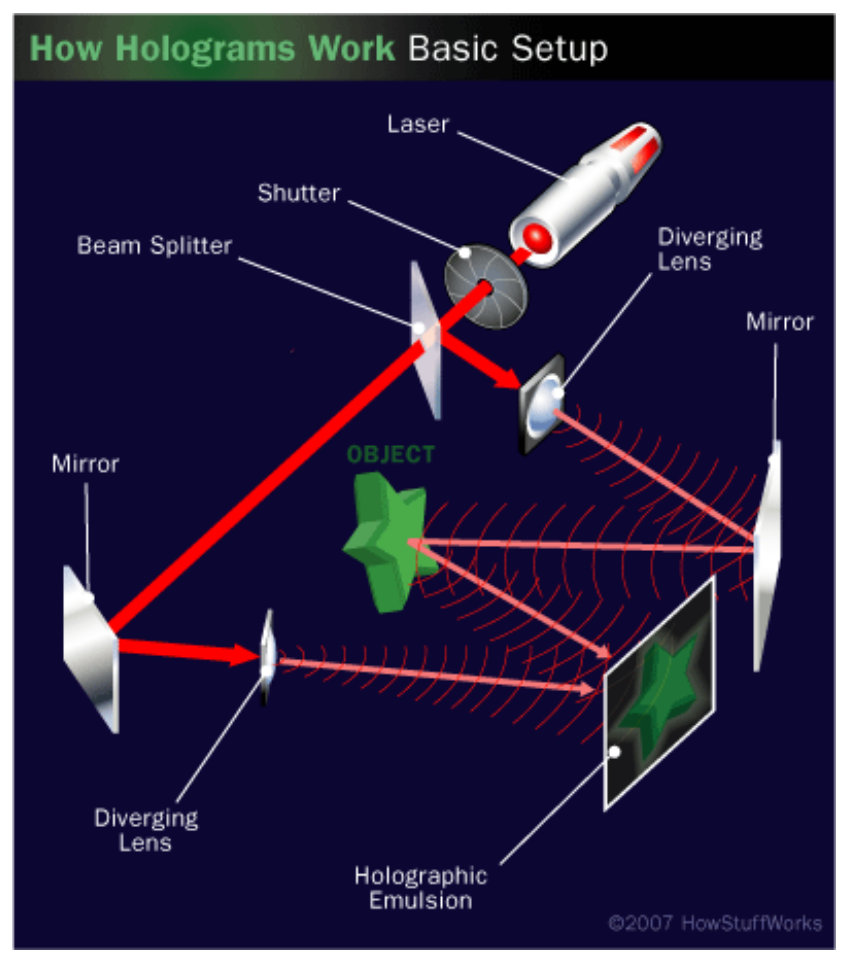

الثكل 3 طريقة تصوير الفلم الهولوجرامي في الهولوجرام المنعكس 
حالة سكون أو حركة ، كالتالي : - reflection hologram -

واهتم هذا النوع من الهولوجرام بتدوين تفصيلات الاجسام ذات العمق المحدود حيث يقوم هذا على انبعاث الليزر ليسقط على الى

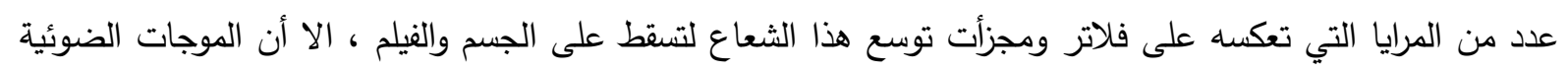

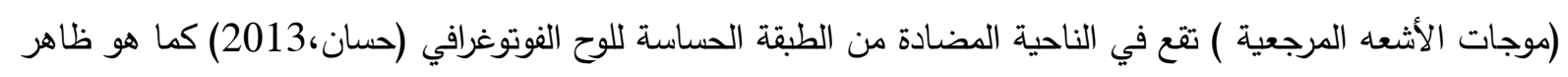

في الثكل رقم (3) (3) (ل)

ويستخدم في استخراج الفلم الهولوجرامي في الهولوجرام المنعكس أشعة الليزر كما ذكر الباحث خالد برهوم في دراسته للهولوجرام وذلك عندما تطلق اشعة الليزر نحو مقسم الاشعه (splitter) فتتقسم الاشعاه لجزئين ينفذ الاول منهما نحو مرآ متساوية مثبته وتعكس الاسعه نحو اللوح الفوتوجرافي وتسمى الاشعه المرجعية ( reference beam) ويسقط الجزء الثاني

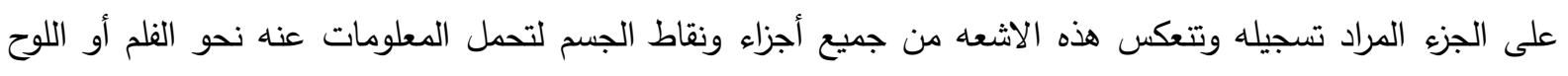
الفوتوجرافيوتسمى هذه الاثععه باشعة الجسم (objective beam) وينتج نمط مركب عن طريق التعاء التقاء الاشععه على سطح

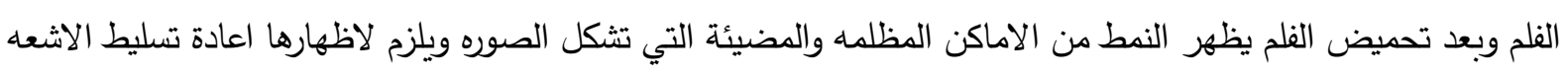

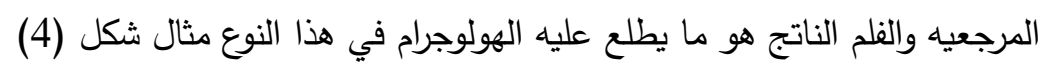

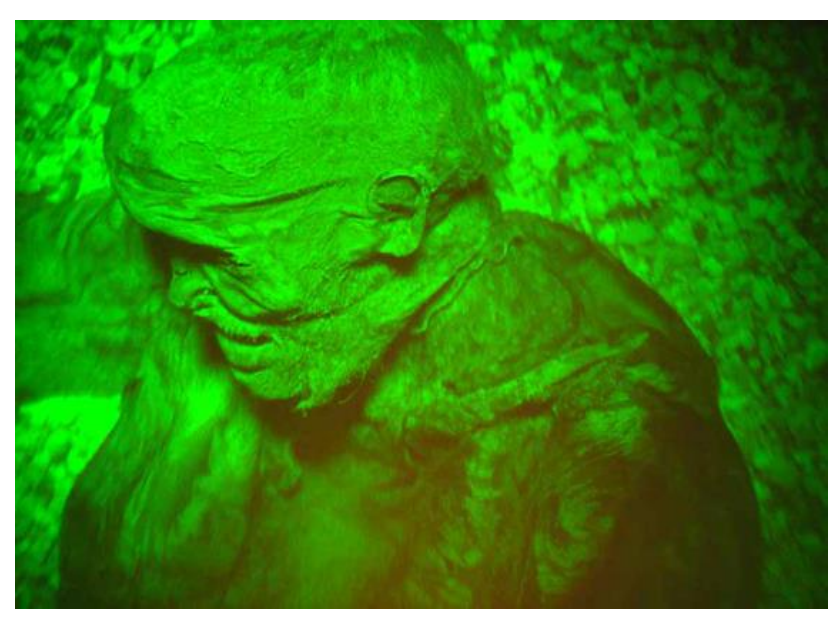

\section{الشكل4 هولوجرام منعكس من قبل استيديوهات ريتشمند الهولوجرامبيه عام 1987 م}

والصوره عباره عن تصوير هولوجرامي لمومياء تم العثور عليها عثر عليها في انجلترا عام 1983 م يعتقد ان عمرها يعود

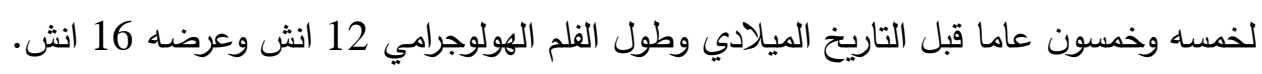
. ( http://nicholasmonsour.squarespace.com/blog/the-light-fantastic.html) من خصائص الليزر المستخدم في تطبيق الهولوجرام كما ذكر في دراسة الباحثة رحاب حماد : 1. النقاء الطبيعي فثعاع الليزر الصادر هو حزمه ضوئية شديدة النقاء من ناحية الطول الموجي وتصدر غالبا من

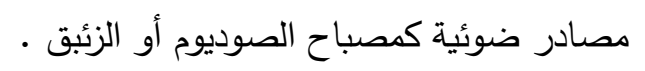

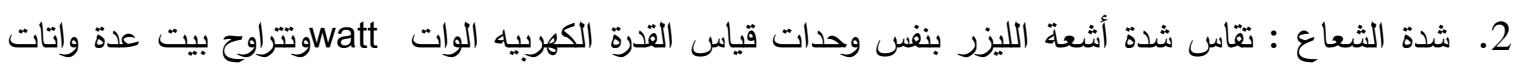
والالاف الملايين من الواتات . 
3. تركيز الثعاع : حيث ان شعاع الليرز حزمه ضوئية رفيعه جدا تتتشر في خطوط مستقيمه اقرب ما تكون الى

التوازي .

4. أحادية اللون : يكون الضوء الناتج عن الليزر عادة احادي اللون غير قابل للتحلل كالضوء الابيض العادي الذي هو عبادة عن تجمع الوان الطيف السبعه وتحلله يعطي هذه النتيجه فالليزر مترابط لا يتحلل حتى باستخدام

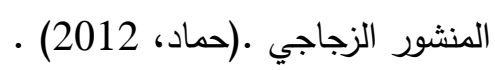

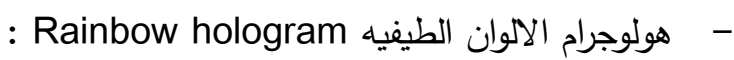

يعرض هذا الهولوجرام صورته من خلال الضوء الابيض العادي وتظهر نتيجته عند تسليط الضوء في صورة ثلاثية البعد

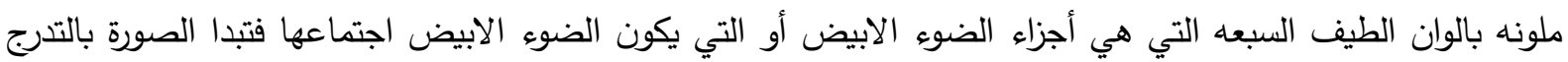

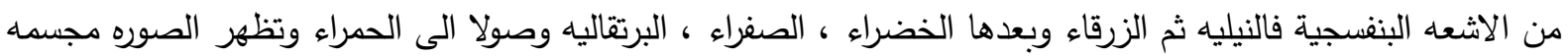
بتحريك الراس حول هذه الصور حيث تحدث تغيرات وتقلبات لونيه تتنشر في اتجاهات متتوعه ولقد استخدمت هذه الصور ، الصداه الهولوجراميه بكثرة في مجال الدعاية والاعلان (حسان،2013) ولعل سبب استخدام الهولوجرام الطيفي الثائع يكون لسهولة مشاهدتها من خلال الضوء الابيض العادي وعدم الحاجة للضوء الليزري المرجعي وقلة تكلفة تصنيعه بالمقارنه مع غيره من انواع الهولوجرام. تجد هذا النوع من الصور الهولوجراميه في العملات والبطاقات الاتمانيه وفي بعض المغلفات للسلع

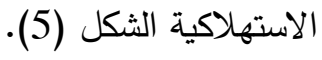

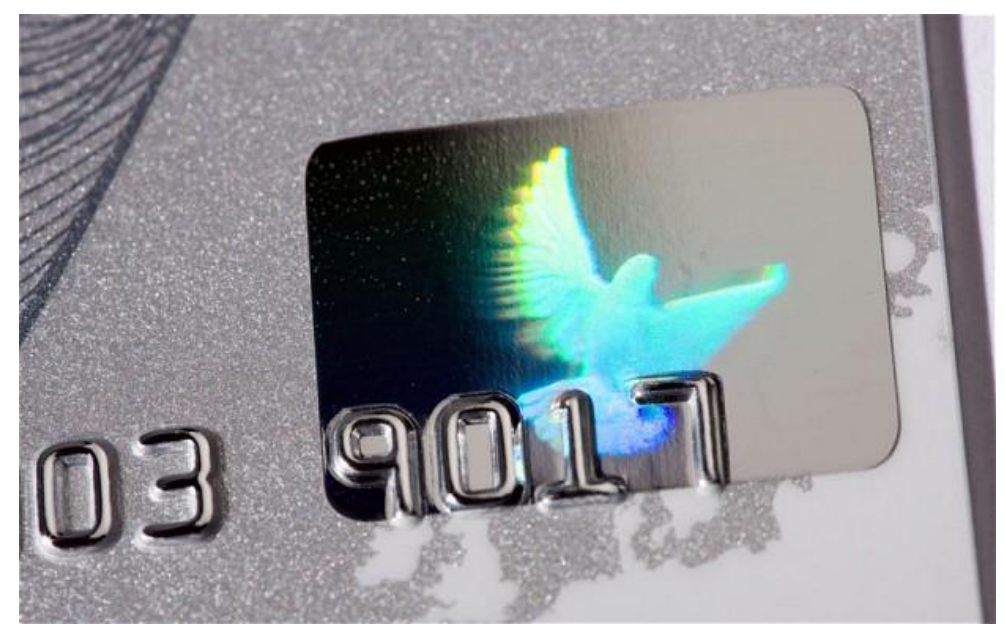

الثكل 5 هولوجرام طني على بطاقة الاتمان

:pulsing hologram - - الهولوجرام النابض -

عند الحاجه لتصوير الصور المتحركه هولوجراميا ظهر هذا النوع من الهولوجرام الذي تم تطويرع خصوصا لهذا الغرض وله

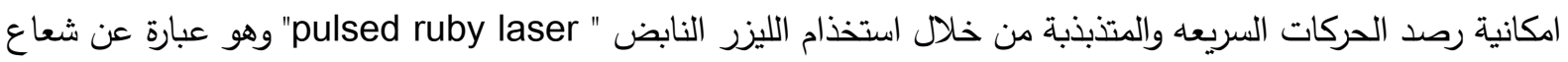
نابض متقطع يختلف عن تلك الاشعه المستمرة التي يرسلها الليزر المعتاد ، حيث يتبع أشكاله ويسجلها بوضوح في أجزاء

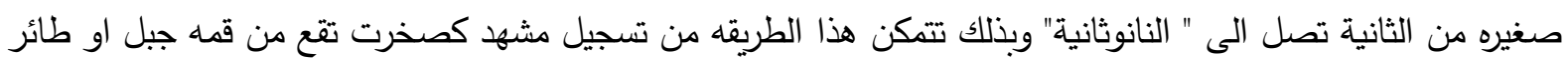
محلق بكل وضوح ودقة.(حسان ، Aerial Burton ريل بورتن اليابانيه أنه وبامكانهر 
الان من خلال هذه التقنيه انتاج اشكال بسيطة في الهواء وخلال ضوء النهار ويعملون على تطوير نتائجهم و الصور التي

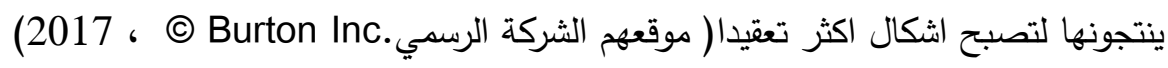

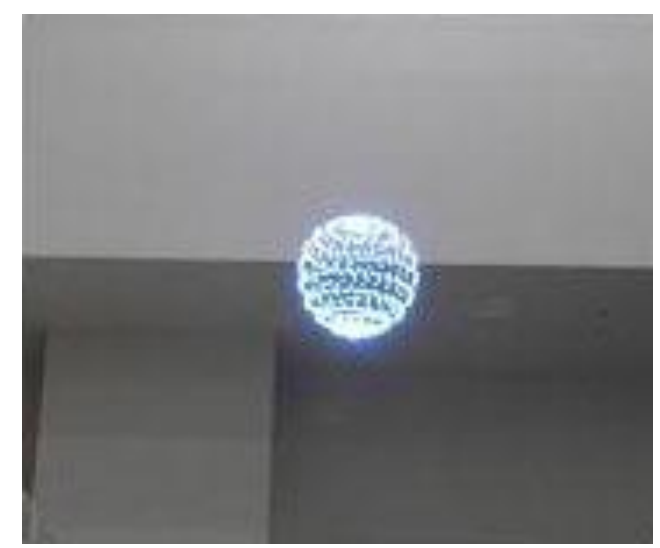

الثكل 6 الليزر النبضي في عرض لثركة اريليورتون.

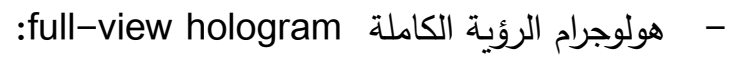

كما يسمى هولوجرام 360 درجة ، ويختلف الهولوجرام هذا في امكانيه مشاهدته من زوايا الثكل كامله بخلاف الانواع السابقه التي بمكن مشاهدتها من 180 درجة فقط ، حيث يتاح للمتفرج الدوران حول الثكل المعروض في شكل فئل اسطواني ورؤية جميع زوايا الفلم ويتم تسجيل هذا الهولوجرام عن طريق وضع الجسم في داخل اسطوانه زجاجيه مغلفه بداخلها بفلم هولوجرامي بحيث تواجه الطبقه الحساسه ذلك الجسم ويمرر شعاع الليزر عبر عدسة تحوله الى حزم ضونئيه متعدده تسقط فوق الجسم و زواياه وتتقلها على الفلم الحساس ( خليل ،2000) ، ويحمض هذا الفلم ثم يعود لمكانه على السطح الأسطواني الزجاجي ويعاد تسليط الليزر المرجعي بنفس طريقة الهولوجرام المنعكس لتظهر الصورة في الفراغ مجسمة تجسيما كاملا ( • (2013، حسان

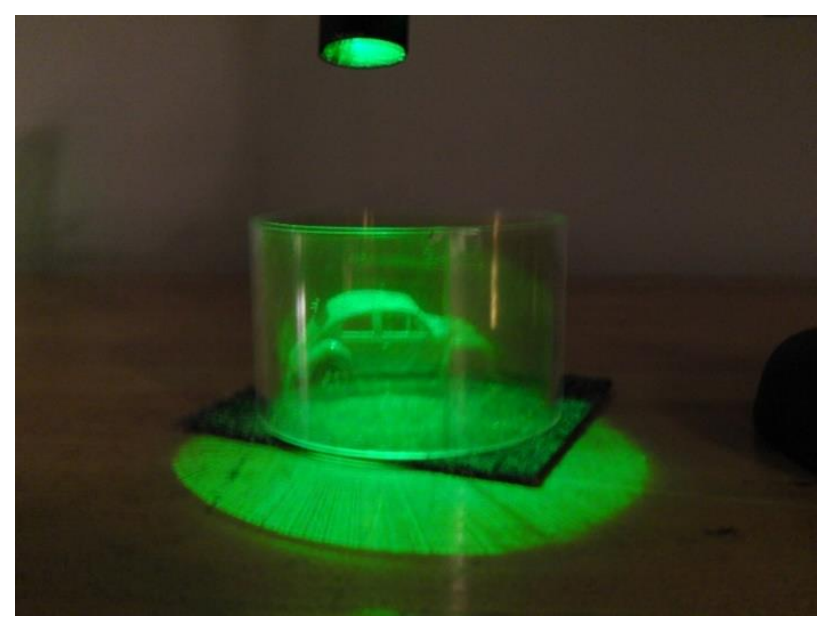

The Regents of the University 2011Copyright الشكل7 هولوجرام الرؤيه الكامله من موقع جامعة ميشيغن of Michigan 
يتميز هذا النوع من الهولوجرامات بأن الصوره به نظيفه وليس بها تشوهات وبالمقابل يعيب على هذا النوع من الهولوجرامات

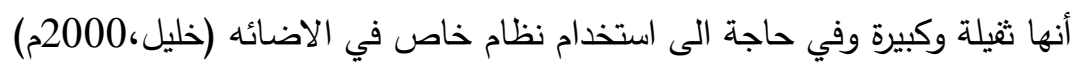
: Integral Hologram - - - -

هذا النوع هو الاكثر حداثة ومرونه حيث يستخدم الضوء الابيض العادي وفي هذا النوع من الهولوجرام الذي طرحه ليولد

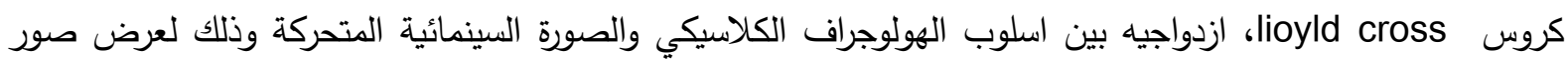
وتصميمات متحركة وذلك بوضع عدد من اللقطات المتتابعه وتحويلها الى لقطات هولوجرام حيث توضع ملتصقة ببعض وذلك من خلال شاشات عرض هولوجرامية خاصة وبذلك نحصل على طريقه عرض هولوجراميه جديده يولدها الضوء

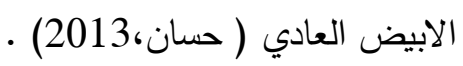

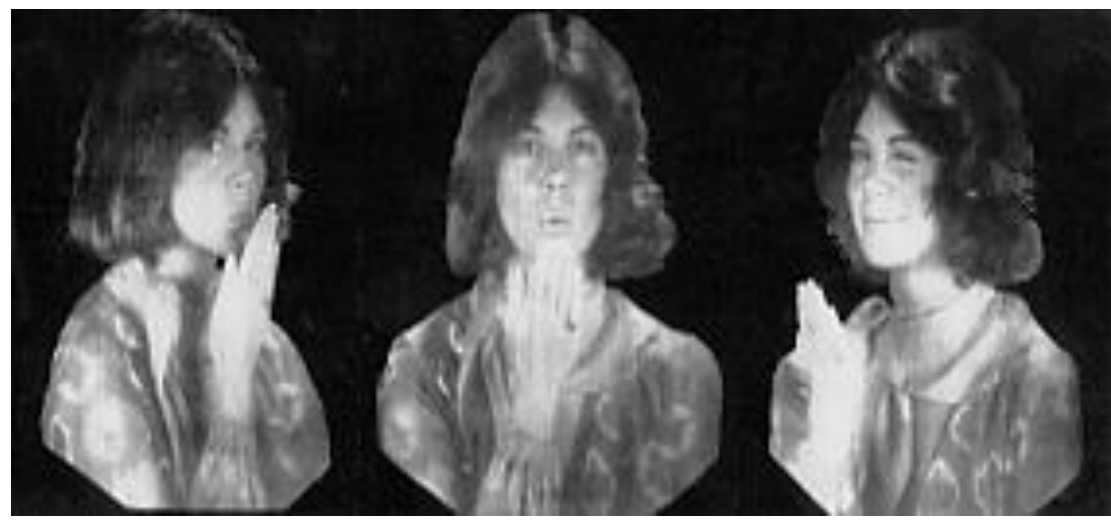

الشكل8 عمل القبله ل لويلد كروس 1974 م هولوجرامتكاملي

ويظهر العمل هذا بثكل اوضح في صور الفيديو حيث ترى الفتاه وانها ترسل قبله في الهواء متحركه عند الدوران حول

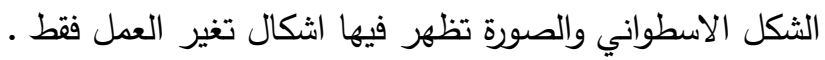

استخدامات الهولوجرام

ان توظيف تقنية العرض الهولوجرامي اتسعت باتساع خيال الانسان وتجمع قدراته الابداعيه والفكريه والعمليه ، وان اغلب العروض العولوجراميه استخدمت في الاهداف الاتي ذكرها :

$$
\text { - - - الهولوجرام في التسويق : - }
$$

بحسب الدراسة التي تتاولت فيها الباحثة مروى كمال الدين أثر الهولوجرام على المشهد الافتراضي للصورة الفنيه ، فانها

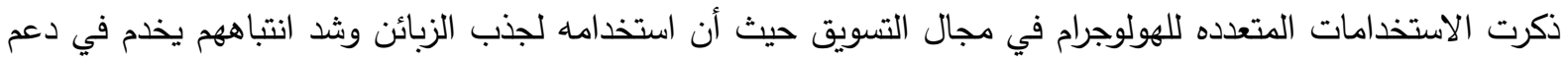
القوة الشرائيه للمنتج وكمثال فان شركة سامسونج استخدمت عرض هولوجرامي حي عند اطلاق هاتفهم الذكي لندن و دبي و سنغافورة (كمال الدين، 2013)

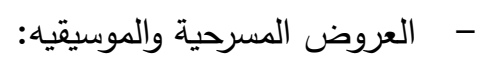

دور الهولوجرام في عروض المسرح هو دور حيوي وفعال يمازج الفنانون من خلاله ادائهم بالتثكيلات الضوئيه والموسيقى

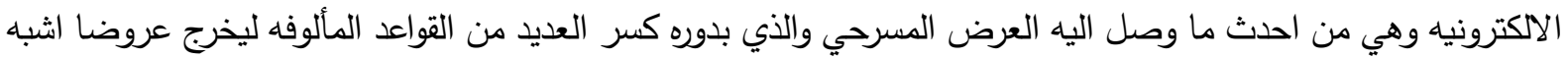


بالاحلام وما تحدثه هذه التقنيه من تجسيمات ضوئيه متفاوته في الحجم مذهله للعين المجرده هي تقنيه اثبه بالمستحيله في

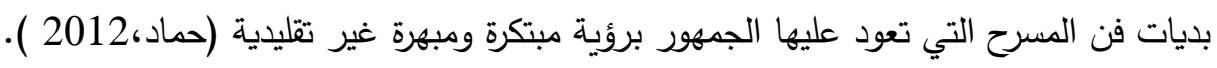

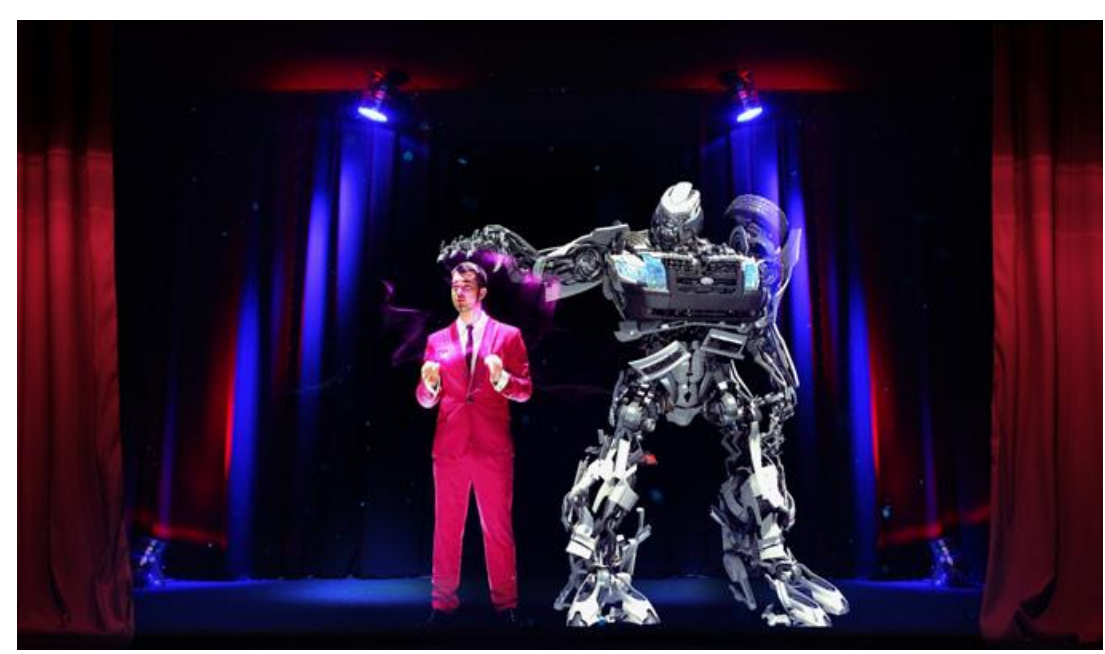

الشكلو الهولوجرام في العرض المسرحي

- - - - الواقع الافتراضي والاتصالات والالعاب التفاعلية:

يختلف مفهوم الواقع الافتراضي والاتصالات الافتراضيه حيث أن الواقع الافتراضي يقصد به الصور التي تولدها اجهزة

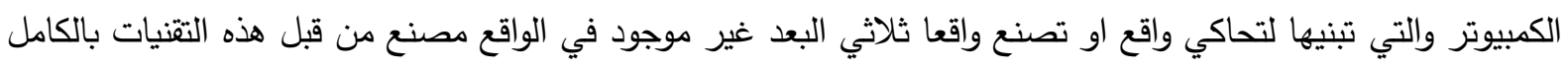

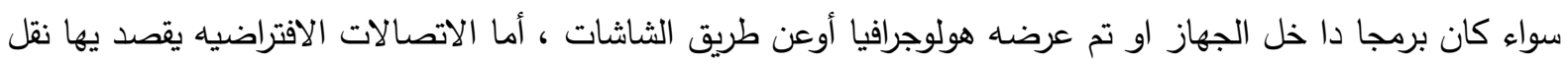

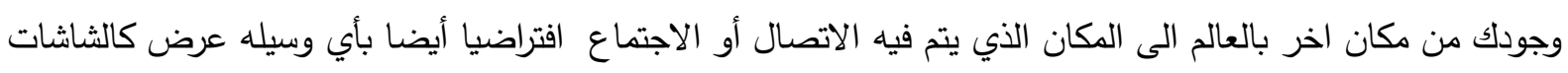

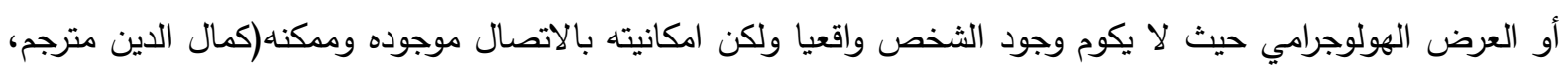

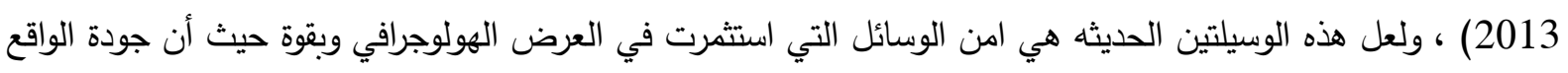

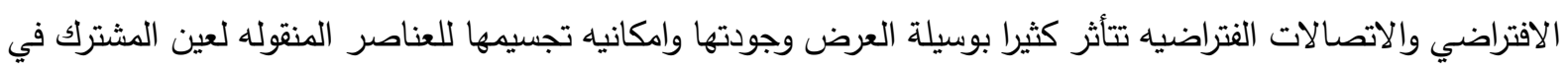
الاتصال أو المتفرج على عرض الواقع الافتراضي .ولعل العاب الفيديو هو احدى مجالات الواقع الافتراضي(كمالالدين

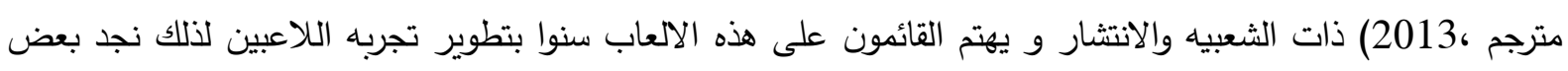

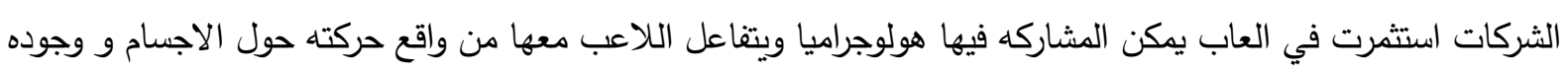

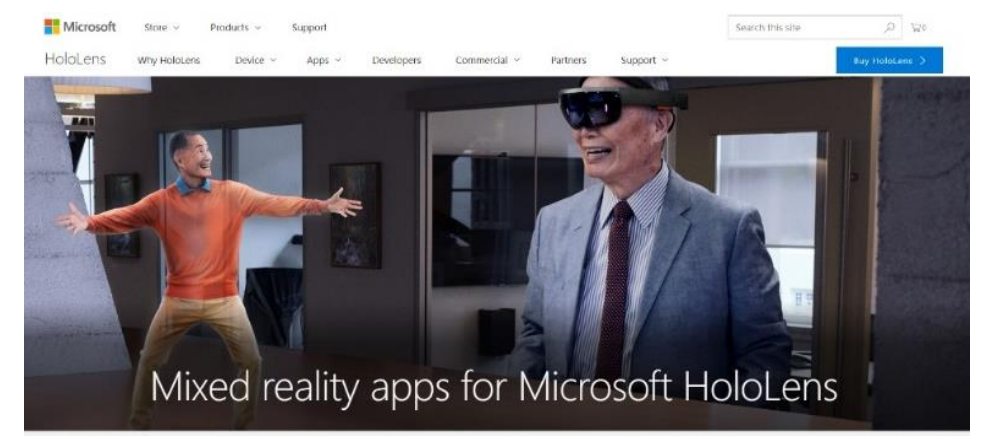

الشكل 10 نظارة من شركتة مايكروسوفت 
ومن أبرز التطورات في هذا المجال النظارة الهولوجراميه التي طرحتها شركة مايكروسوفت وتمكن هذه النظارة المستخدم من

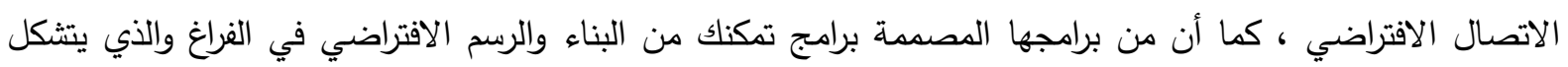
بصورة ثلاثية البعد يراها كل من يستخدم النظارة وكانها بيانات ثلاثية ابعاد محفوظة في ذاكرة الجهاز وهذا التطور الهائل

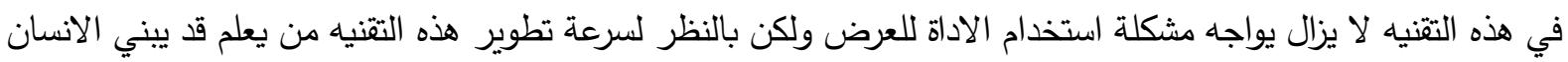

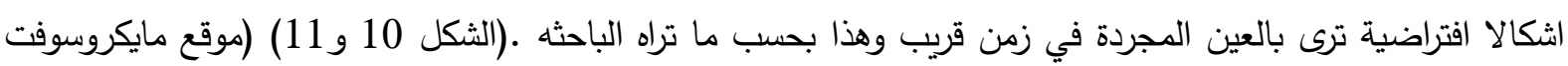

الرسمي)

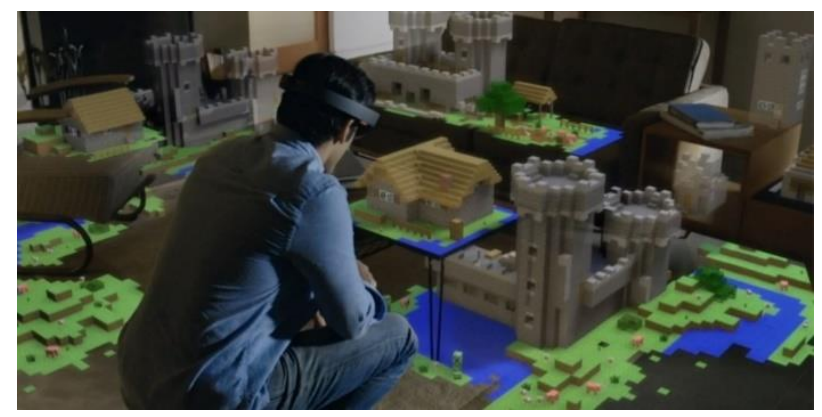

الثكل العبة التي طوتها لثركة مايكروسوفت ونظارتهم الهولوجرامبيه

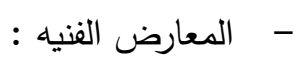

وقد اقيمت العروض الداخليه والخارجية وفي عام 1969م استضافت أكاديمية الفنون بولاية ميشيغان الامريكية أوائل

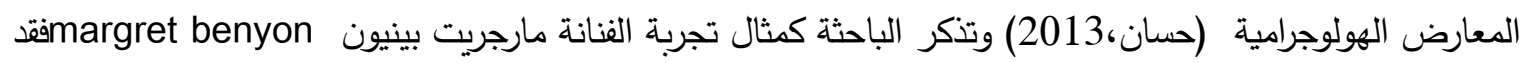

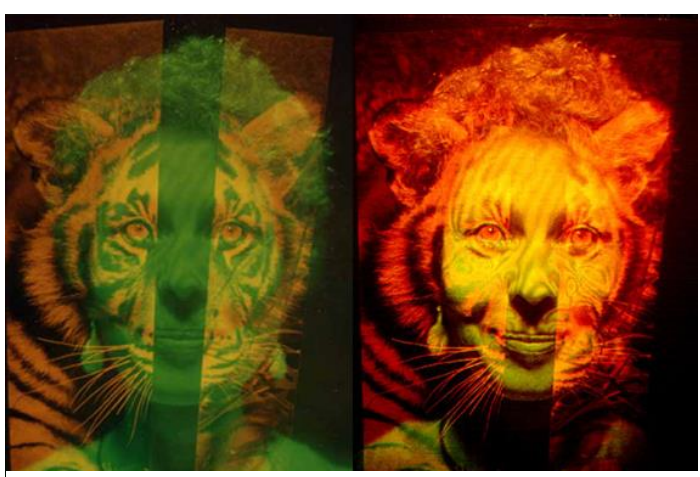

1الشكل 12 مارغربت بينيون

اجرت عددا من التجارب على الهولوجرام وتقنياته المتعدده في عام 1986م فاستخدمت الهولوجرافات احادية اللون ، هولوجرافات طيفية، هولوجرافات نابضة ، وفقا للمفهوم التي تتطوي عليه رسالة العمل الفني وقد وظفت الفئ الفنانة الليزر

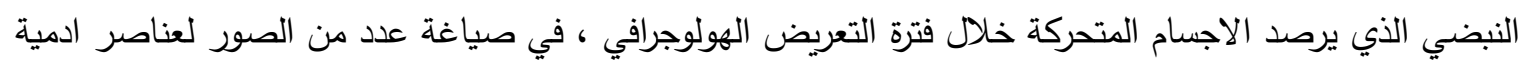

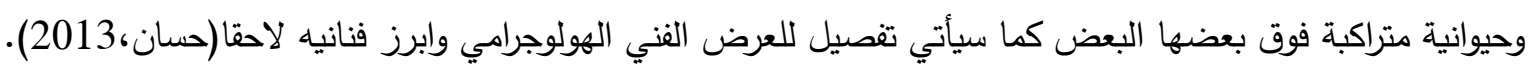


لعل من ابرز فناني القرن العشرين الذين اختبرو المفهوم والماد الفنيه بطلاقه عجيبه وبحريه مطلقه هو سلفادور دالي ، مؤسس السيرياليه الفنان الاسباني سلفادور دالي والتي امتازت اعماله بالغرابة والتكوينات الغير مألوفة والفريدة كما أيضا

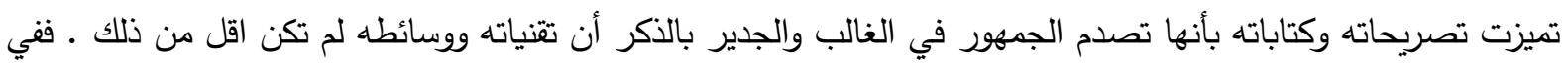

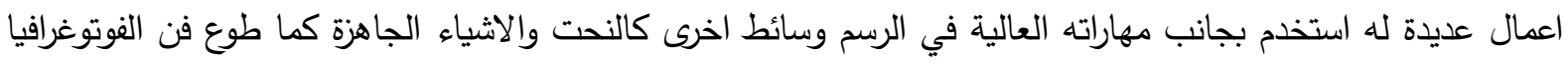

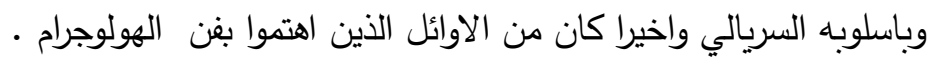

وفي مقالة لسيلوين ليساك " Selwyn Lissack "وهو فنان من جنوب افريقيا أسس مدرسة الهولوجرام والتصاميم الهولوجراميه في نيويورك ، نشرت في 2014 على موقع الجمعية العالمية للبصريات والفوتوغرافيا تحدث فيها عن تعاونه مع الفنان لانتاج

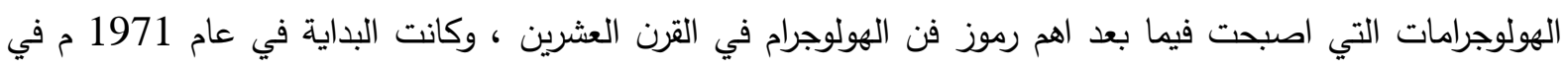

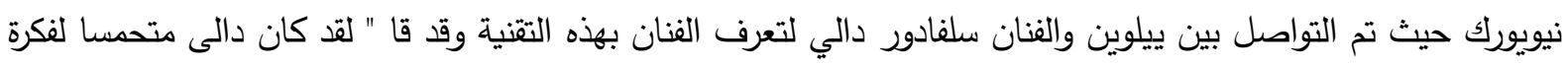

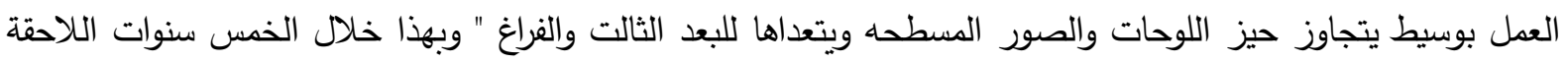
كان الفنان يعمل بالتعاون مع هذه المجموعه لابتكار ومناقثة وتنفيذ سبعه هولوجرامات كانت الواجهه الابرز لتثكيل فن

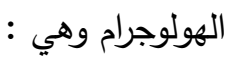

$$
\begin{aligned}
& \text { Brain of Alice Cooper } \\
& \text { Crystal Grotto } \\
& \text { (وتعني احتفال لوحات دالي) Dali Painting Gala }
\end{aligned}
$$

Melting Clock عليه حتى عام 2003 م بعد ادخال اختراع ضوء

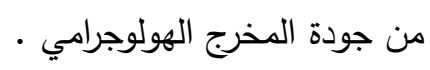

والجدير بالذكر هي أن التكنولوجيا الهولوجراميه في السبعينات كانت محدودة بالمقارنه بما وصلت لها التقنيه الان فبذلك كانت هنالك نوع من القيود المفروضه على الفنان سلفادور دالي ومع ان اضافته لفن الهولوجرام كانت نوعيا وهائلة

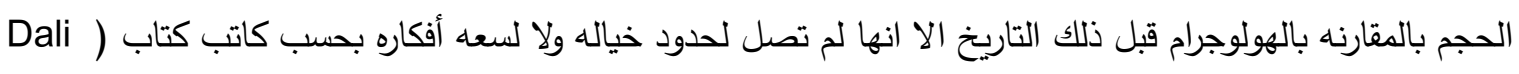
(in Holographic Space 


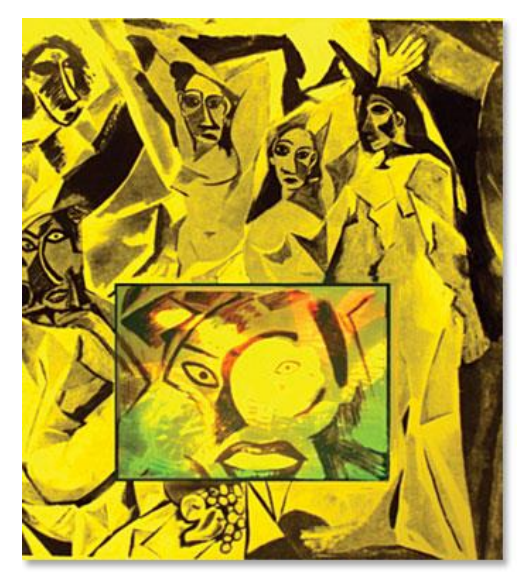

الشكل 13 هولوجرام سلفادور دالي (صياد الغواصه)

وفي عمل سلفادور دالي الهولوجرامي ( صياد الغواصة ) الذي تم انجازه عام 1971م ، استخدم الهولوجرام الشريحي الطيفي ليضيف بعدا ثالثا للوحة بيكاسو الثهيرة The Young Ladies of Avignon وصورة احدى فتيان اللوحة مكبرة وفي تصريح دالي يقول انه استلهم في هذا العمل من نظريات فرويد عالم النفس التي تتحدث عن العقل اللاواعي ويعد من أعمال

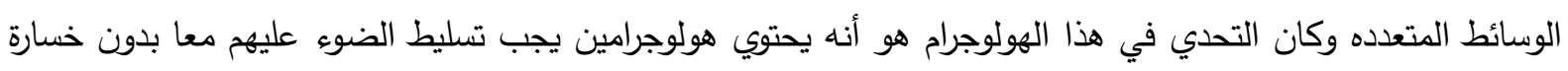

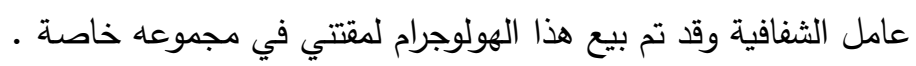

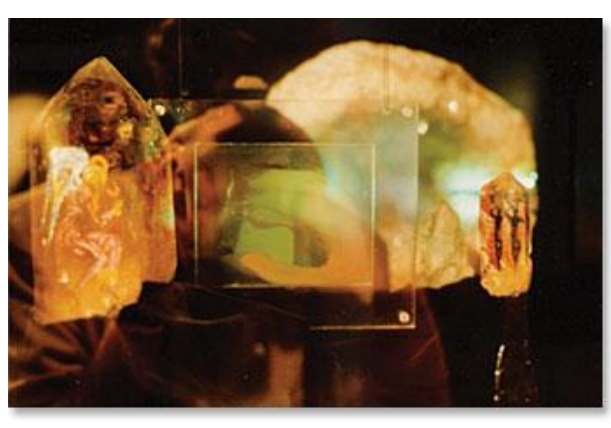

\section{الشكل14 عمل سلفادور دالي الهولوجرامي (كهن الكريستال)}

اما عمل الفنان سلفادور دالي ( كهف الكريستال ) الذي تم انجازه في عام 1971 م كذلك فيعتبره بوابه الى الجنه وهو عمل كولاج ثلاثي الأبعاد من انعكاسات كريستاليه على افلام هولوجراميه تعكس اعتقادات سلفادور دالي الروحية العمل تم تتفيذه فئه

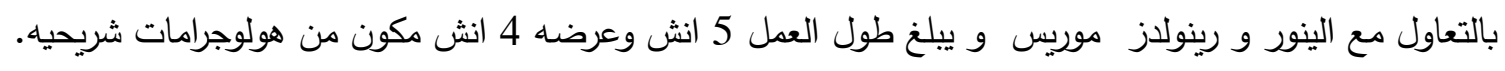

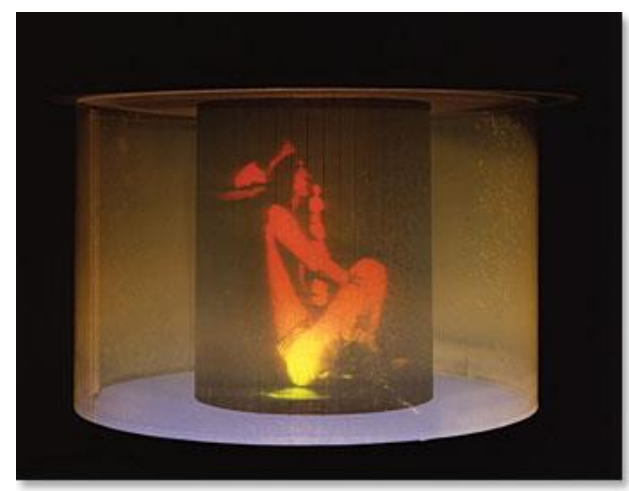

$$
\text { الشكل } 15 \text { عمل سبلفادور دالي بهولوجرام } 360 \text { درجة (عقل اليس كوبر) }
$$




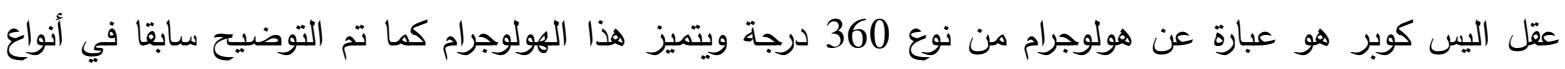

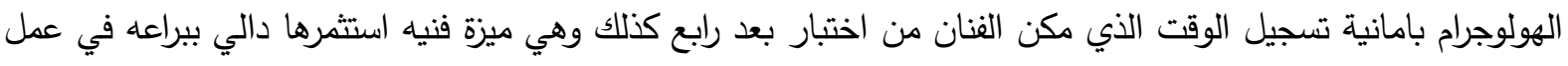

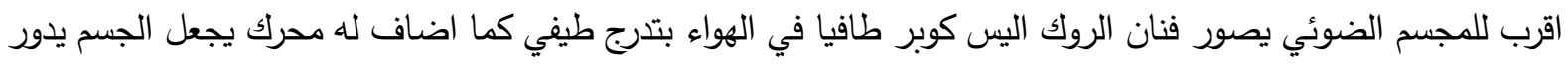

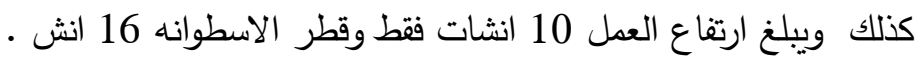

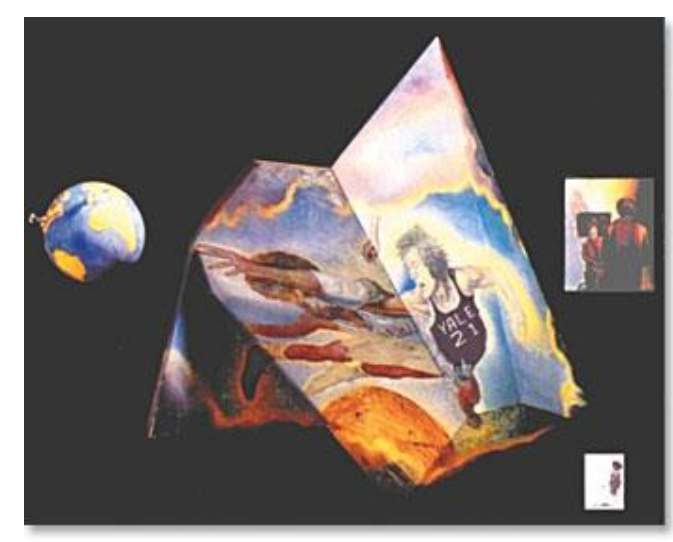

\section{الشكل 1عل سبلفادور دالي الهولوجرامي ( المنشور )}

وفكرة سيلفادور دالي في هذا العمل كانت بأن يعمل على اسطح مجسمه في الفراغ ومن ثم يذهب بها الى الاستديو

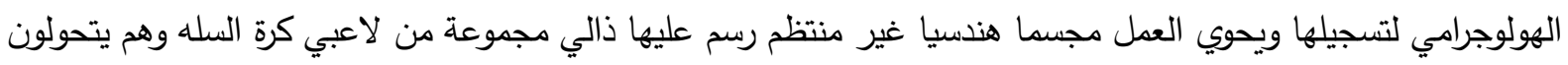

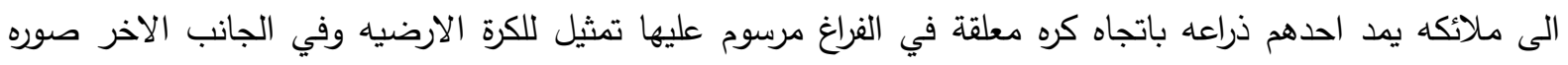

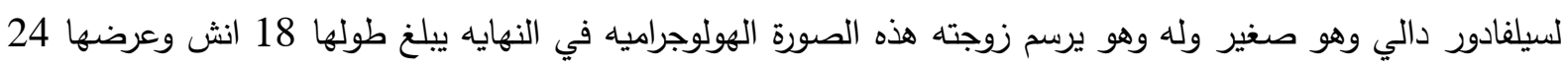
انش وتم انجازها في عام 1972 و هي الام مملوكة ضمن مجموعة خاصة.

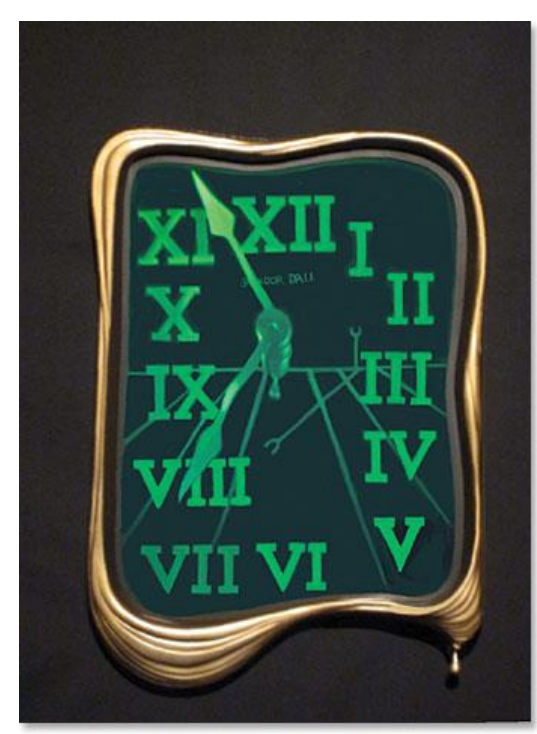

الشكل17 الساعه الهولوجرميه الذائبه تصميم سلفادور دالي

واخر مثال هولوجرامي يعكس عبقرية دالي التي سبقت وقته وتتنيات عصره هي الساعة الذائبه الهولوجراميه التيصمها

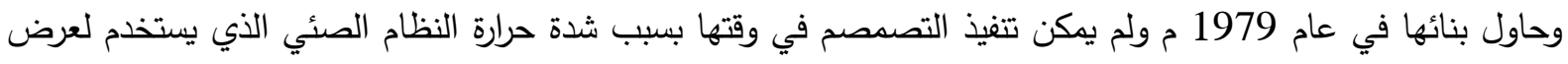

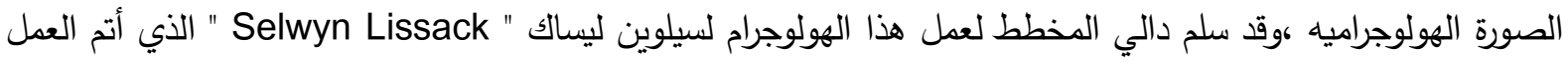


عليها في عام 2003 بالتعاون مع شركة Laser Reflections والذين يمتلكون معملا هولوجراميا مجهز بتقنيات تسمح بتتفيذ الفكرة ( موقع الجمعية العالمية للبصريات والفوتوغرافيا). تجربة الباحثة التصوريه

أن أول اهتمامات البحث في مجالات تطبيق الهولوجرام وكيفياتها هي بهدف المساعدة على ادخال هذا الوسيط الفني في قائمة البحوث التطبيقية العربيه المفيدة والبنائة وصفيا وعمليا ـ وبالنسبه للتطبيق الهولوجرامي في المعامل المتخصصه فانيان

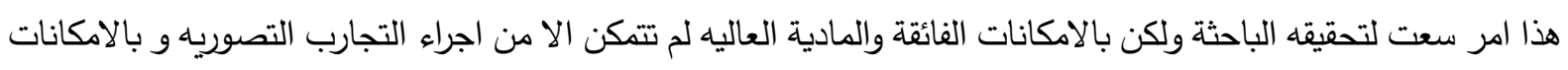

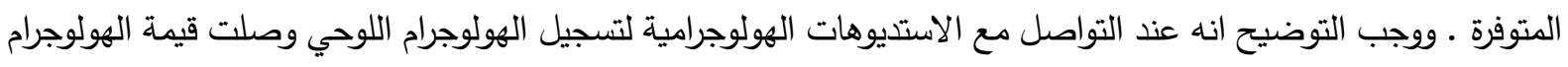

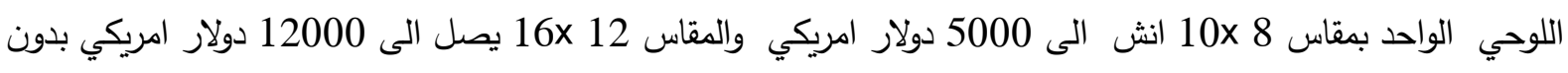

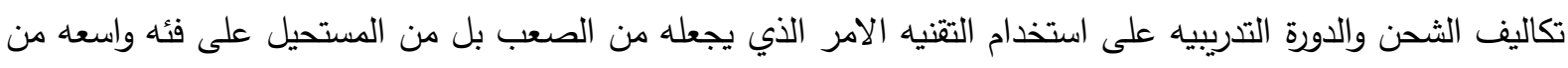

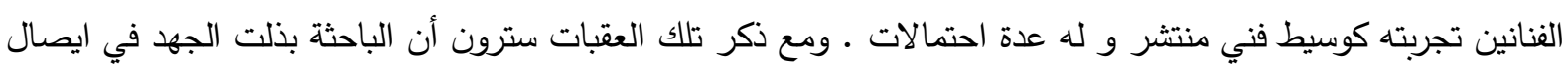
فكرتها للهولوجرامات ومواضيعها المفاهيمية.
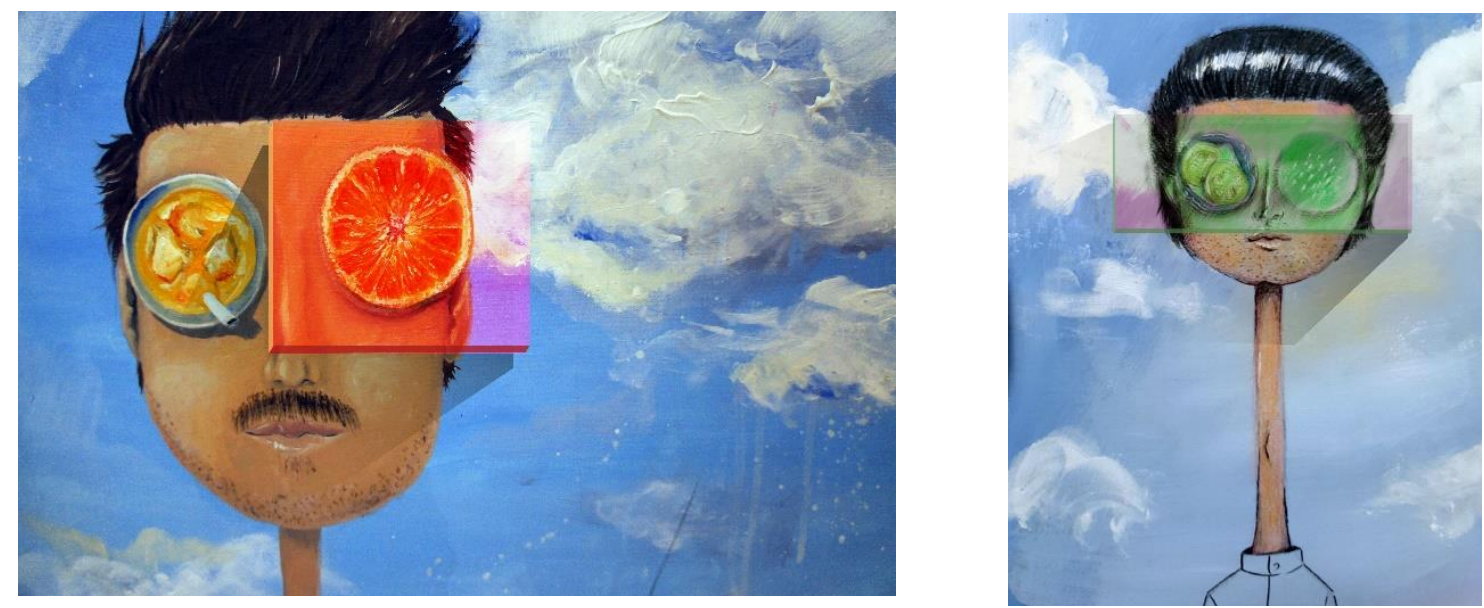

\section{اللوحة التصوريه رقم 1و 2}

اللوحة (1)على اليمين لوحة مفاهيمية استخدمت فيها الباحثة الاسلوب المفاهيمي في الفكر والسيريالي في التصوير الفني الوان اللوحة الهادئه ( السماء ) وغيومها تتاقض الهولوجرام المعلق امام عين الثاب الذي يبدو وكأنه ينظر من خلال ساندويش البرجر المجسم هولوجراميا بدرجات ظل احادية وهذا تأثير الهولوجرام اللوحي الذي يتم تصويره بليزر لون واحد منفرد.

لوحة (2) هنا تستخدم الباحثة أيضا الاسلوب المفاهيمي في التعبير والسيريالي في التصوير حيث أن العناصر الطبيعيه

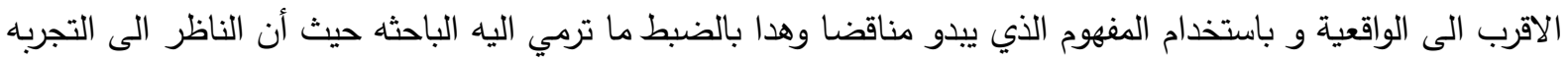

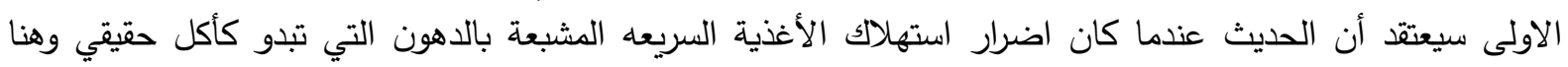
2النقيض فالبرتقال نوع من الغذاء صحي هنا تسأل الباحثة وماذا عن الأغذية المعدلة وراثيًا؟ 


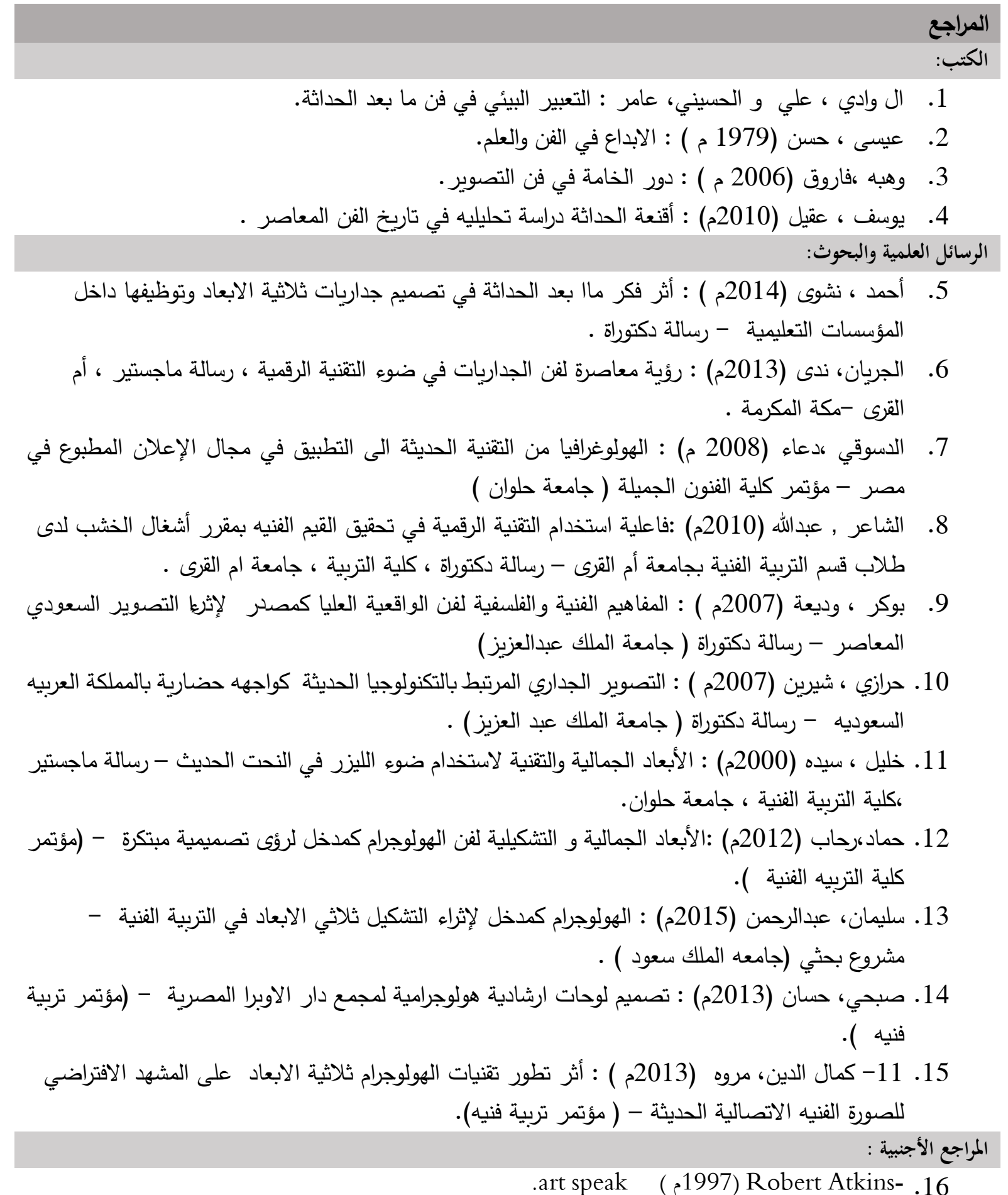

$$
\text { .art speak （1997) Robert Atkins- .16 }
$$

New media in art -second edition (Michael Rush2005) .17

"?Michael Anissimov (2017), "What is Technology .18

Young,Duncan (fine art application of holography: the historical significance of

light and the hologram in visual perception and artistic deception (PHD) 1997

Spatial augmented reality merging p ) : 2005(bimber, ramesh raskar and others. - .20 real and virtual worlds 